\title{
TRADUÇÃO INTERSEMIÓTICA E REPRESENTAÇÃO CULTURAL EM FILMES BRASILEIROS: UMA CONSTRUÇÃO NARRATIVA
}

\author{
Sinara de Oliveira Branco* \\ Universidade Federal de Campina Grande ${ }^{1}$
}

\begin{abstract}
Resumo: Este artigo apresenta a construção de um corpus multimodal, ou seja, um corpus formado por recursos audiovisuais. Neste caso, o corpus é construído a partir de dois filmes nacionais (Cidade de Deus e $O$ Auto da Compadecida), tendo a imagem como fonte para a construção da narrativa nessas obras de ficção. $\mathrm{O}$ trabalho tem arcabouço teórico relacionado à Tradução Intersemiótica e à Representação Cultural com o objetivo de mostrar que, apesar de os filmes apresentarem linguagens específicas, retratando o povo brasileiro em contextos espaço-temporais específicos, a compreensão da história narrada não é comprometida mesmo que haja necessidade de omissão da linguagem verbal nas legendas em inglês, pois as imagens são capazes de traduzir os fatos retratados, não causando perda de sentido ou falha na comunicação. Para o desenvolvimento do estudo, serão compiladas cenas dos dois filmes para serem analisadas em sequência e planos específicos, observando o tema abordado em cada filme e as informações culturais apresentadas em tais planos. A pesquisa a ser desenvolvida tem duas perspectivas: i) a compilação e construção de um corpus multimodal de imagens fílmicas que represente culturalmente o Brasil, independentemente do contexto regional e temporal; ii) descrição da representação cultural retratada nas imagens fílmicas em contexto nacional.
\end{abstract}

\footnotetext{
* Mestrado e Doutorado pelo Programa de Pós-Graduação em Inglês (PGI) na área de Estudos da Tradução da Universidade Federal de Santa Catarina. Professora de Letras/Inglês na UFCG, com ênfase em Tradução. Pesquisadora, coordenadora e professora do Programa de Pós-Graduação em Linguagem e Ensino da Universidade Federal de Campina Grande (UFCG). Campina Grande, Paraíba, Brasil. E-mail: sinarabranco@gmail.com
} 
Palavras-chave: Tradução intersemiótica. Multimodalidade. Representação cultural.

\title{
INTERSEMIOTIC TRANSLATION AND CULTURAL REPRESETNATION IN BRAZILIAN FILMS: A NARRATIVE CONSTRUCTION
}

\begin{abstract}
This paper presents the compilation of a multimodal corpus using two Brazilian films (Cidade de Deus and $O$ Auto da Compadecida), considering the image as a source for narrative construction in both films. The theoretical framework includes Intersemiotic Translation and Cultural Representation in order to show that, although the films selected present specific ways of speaking portraying Brazilian people in specific spatio-temporal contexts, the comprehension of the narrated stories is not compromised even with the need for omitting some speeches in the subtitles in English, because of the fact that the images are able to translate the portrayed facts, not causing loss in meaning or lack of communication. The methodology includes the compilation of scenes of the two films to be analysed in specific sequence and plans as well as the observation of the theme explored in each film, besides the cultural information presented in the plans. The research to be carried out has two perspectives: i) the compilation and construction of a multimodal corpus of images that represent Brazil culturally through films, regardless of the regional and temporal contexts; and ii) the description of the cultural representation portrayed by the filmic images in national context.
\end{abstract}

Keywords: Intersemiotic translation. Multimodality. Cultural representation.

\section{Introdução}

Este artigo propõe o desenvolvimento de um estudo que alie a categoria intersemiótica de tradução de Jakobson (2000) a teorias específicas de Tradução e Cinema, voltando-se para uma análise de construção narrativa e de questões culturais através de filmes que representam o Brasil (ou 'Brasis') em diferentes regiões do país. Os filmes selecionados são Cidade de Deus ${ }^{2}$ e $O$ Auto da Compa- 
decida ${ }^{3}$ - o primeiro sendo ambientado no Rio de Janeiro dos anos de 1960 e 1970 e o segundo, no nordeste brasileiro dos anos de 1930. O objetivo é investigar a representação de Brasil nesses dois contextos, a partir da análise de imagens dos filmes e, quando necessário, compará-las à linguagem utilizada nas legendas, buscando mostrar que a possível 'intraduzibilidade' linguística, em momentos específicos dessas duas produções fílmicas, é superada pelo uso de imagens que traduzem as mensagens, muitas vezes sendo possível deixar o uso de legendas em segundo plano, ou mesmo omiti-las, sem perdas de sentido na construção narrativa da história.

As obras selecionadas retratam o Brasil em perspectivas espaço-temporais distintas. O Auto da Compadecida é uma comédia ambientada no sertão da Paraíba, entre as cidades de Taperoá e Cabaceiras, na década de 1930. Os personagens são cômicos ${ }^{4}$, usando o termo segundo Aristóteles (1999), que o descreve com referência ao ser inferiorizado, considerado tolo, feio, com falhas de comportamento, com modo de vestir característico e tímido. Essas são características dos personagens João Grilo e Chicó, que possuem linguagem que resguarda a maneira de falar e agir do sertanejo, utilizando a melodia e trejeitos do morador típico da região. Apesar do fato de que as falas dos personagens são breves e sucintas, elas são, ao mesmo tempo, carregadas de expressões típicas e comuns geralmente aos que (con) vivem na região, causando dificuldades de compreensão até mesmo a brasileiros de localidades distintas. Muitas expressões são, portanto, omitidas nas legendas, talvez por serem consideradas 'intraduzíveis' na forma verbal. Neste caso, será observado até que ponto as imagens auxiliam na tradução de significados das cenas/situações.

O filme Cidade de Deus, por sua vez, é ambientado em uma favela do Rio de Janeiro, entre as décadas de 1960 e 1970, e é baseado em fatos reais extraídos do romance homônimo de Paulo Lins $^{5}$. Cidade de Deus é o filme que marca, segundo Oriccchio (2003), o encerramento da era do Cinema da Retomada, que teve início em 1995, após a crise no cinema nacional durante o Governo Collor. A montagem de Cidade de Deus é diferente da montagem 
de $O$ Auto da Compadecida, apresentando cenas mais dinâmicas e uma sequência mais rápida entre as cenas. O filme inicia pelo final, como em Pulp Fiction ${ }^{6}$, do diretor Quentin Tarantino, e vai voltando, numa narrativa cronológica entre os anos de 1960 e 1970, descrevendo a cultura dessas duas décadas através de sua vestimenta, atitudes, falas e músicas. O conjunto habitacional do Rio de Janeiro, chamado Cidade de Deus, é o cenário para a construção dramática da obra, que mostra como o tráfico de drogas foi sendo constituído e como o seu contexto violento foi se apoderando de crianças e adultos. A linguagem narrativa do filme é marcada por um tom irônico, que descreve a situação de segregação local de seus moradores, assim como o crescimento da notoriedade dessa comunidade através da violência e do tráfico de drogas, inclusive com a conivência da polícia. Nesse filme, a linguagem também é típica do local e da época, e as expressões, muitas vezes, são omitidas nas legendas, também pela possível 'intraduzibilidade' linguística. Mais uma vez, será observado o auxílio das imagens na tradução de significados das cenas/situações.

Para melhor compreender a questão tradutória envolvendo imagens fílmicas e representação cultural, serão apresentados, a seguir, pontos que envolvem esses aspectos.

\section{Tradução intersemiótica, cinema, representação cultural e multimodalidade}

Aumont e Marie (2004) afirmam que a análise fílmica, de maneira geral, é uma tarefa que deve ser diferenciada da crítica de cinema, pois, ao dissociar elementos específicos de um filme para um estudo aprofundado, deve-se oferecer uma análise que produza conhecimento e que não seja meramente uma apreciação. Em outras palavras, os autores consideram a análise fílmica uma atividade descritiva e não modeladora, que parte do fílmico e vai até uma reflexão ampla do fenômeno cinematográfico. 
Para obter uma análise sistemática do cinema, ou seja, uma análise que envolva teorias sobre Cinema combinadas a outras áreas - como a Tradução Intersemiótica, por exemplo -, deve-se partir de elementos reconhecíveis nas imagens fílmicas selecionadas para construir relações lógicas a partir de: i) instrumentos descritivos (que são características de som e imagem); ii) instrumentos citacionais (que são o estado intermediário entre o filme e o exame analítico); e iii) instrumentos documentais (que são as informações coletadas além do filme) (AUMONT; MARIE, 2004, p. 39 e 45-46). No escopo aqui estudado, os elementos descritivos são as imagens selecionadas dos filmes escolhidos, associadas a teorias específicas para análise, além dos aspectos do filme em si, investigados em contextos específicos, como o brasileiro do norte/nordeste e sul/ sudeste, por exemplo.

Os pontos mencionados acima partem da ideia de que, devido à vastidão do território brasileiro, é comum ver o cinema retratar vários 'Brasis' em suas telas. Consequentemente, os costumes, hábitos, linguagens e práticas culturais são traduzidos para todos os cantos do país - e do exterior. De acordo com Cronin (2009), ao se pensar em tradução no cinema, ainda há necessidade de mais estudos voltados para questões que abordem os dilemas da tradução em filmes. $\mathrm{O}$ autor parece fazer referência a um estudo sobre tradução em cinema que vá além de questões técnicas de legendagem, envolvendo outras formas de tradução - como a utilização de recursos imagéticos. Neste caso, especificamente, serão tratadas questões sobre a tradução intersemiótica, ou seja, a tradução que se refere às imagens e não necessariamente à legenda. Complementando a colocação de Cronin (2009), Aumont e Marie (2004, p. 141) afirmam que "o ponto de vista é o lugar a partir do qual se olha. De forma mais abrangente, é também a maneira como se olha". Os autores explicam que, em análise de filme narrativo, é essencial mostrar a relação entre o ponto de vista de quem narra e dos demais personagens. Nesse caso, além das imagens, parece relevante observar a fala do narrador e a dos personagens da trama. 
Para tratar da questão da enunciação/ficção, ou seja, "o dito e o dizer", que envolvem o ponto de vista, o filme apresenta a sua forma de realização, que engloba o discurso dos olhares e enquadramentos (enunciação): cada colocação da câmera e pontos de vista variados vão constituir a enunciação, envolvendo o espectador na trama (BROWNE, 1982). Aumont e Marie (2004, p. 145) afirmam que "o trabalho do espectador consiste em estabelecer permanentemente esse vínculo entre ficção e enunciação, ao passar de uma situação de puro espectador 'mantido à distância' [...] a um estatuto activo que o leve a identificar-se com o acto da enunciação [...]". Um exemplo disso é o narrador do filme Cidade de Deus, que é narrador-personagem, e apresenta a história sob sua ótica, oferecendo ao espectador espaço para observar e participar da trama, de acordo com a diegese por ele apresentada.

No contexto do cinema, os autores citados afirmam ser praticamente impossível analisar a narrativa fílmica desconsiderando o aspecto visual. Ao mesmo tempo, seria insípido analisar as imagens isoladamente. Nesse aspecto, em se tratando de análise fílmica, investiga-se a fala e a voz à luz da pragmática e do estudo do oral, além da análise psicanalítica da voz (AUMONT; MARIE, 2004, p. 204-5). Entretanto, como já mencionado, é necessário investigar mais atentamente questões que envolvam a tradução fílmica em diversos aspectos - imagens, legendas e representação cultural dentre esses. Os constituintes da narrativa - o narrado, o descrito e o dialogado (cf. VANOYE, 1979) - podem ser investigados à luz da tradução associada à narratologia, e essa é a intenção aqui. Vanoye (1979) cita a omissão de traços característicos da linguagem oral em filmes ao serem transcritos para publicação. Os recursos utilizados para tais omissões são pausas ou silêncios, por exemplo. Esses recursos são também utilizados em legendagem e são percebidos nos filmes selecionados, observando que há uso de recursos pragmáticos que acompanham a comunicação oral: trocas por elementos verbais e de entoação. Além desses recursos, não é possível deixar de lado a referência à 
psicanálise freud-lacaniana, que observa a relação entre produção de sentido e sujeito falante.

Aumont e Marie (2004, p. 66-67) afirmam que a dificuldade de descrição de imagens fílmicas está associada ao fato de que a descrição é seletiva, tendo a imagem vários níveis de significação, veiculando elementos informativos e simbólicos. Portanto, "ao descrever uma imagem, a primeira tarefa do analista é identificar corretamente os elementos representados, reconhecê-los, nomeá-los" (Ibid., p. 67). Dessa forma, neste estudo, crítica e teoria literárias são associadas a teorias de tradução e cultura para a análise da aplicação da tradução intersemiótica na investigação de representação cultural em contexto fílmico. Desse modo, este artigo está inserido no campo dos Estudos da Tradução, do Cinema e da Representação Cultural, especialmente na tradução de multimídia ${ }^{7}$ e, mais especificamente, no estudo das questões culturais e seu papel na formação e transformação das sociedades.

Nesse sentido, ao se trabalhar com imagens fílmicas, faz-se uso de um corpus multimodal que facilite a investigação de questões culturais exploradas nas narrativas fílmicas, bem como a forma como é construída a representação - através da tradução - de tais contextos culturais. Multimodalidade é explicada aqui de acordo com Lund (2007, p. 289-290), que afirma que tal terminologia diz respeito a emoções e atitudes transmitidas pela prosódia, apreciação, riso ou silêncio, em resposta a um questionamento, atitude, movimentos corporais, manipulação de objetos etc. O termo multimodal também é aplicado para indicar recursos midiáticos utilizados para comunicação de mensagens, por exemplo, através de linguagens verbais e/ou não verbais. Nesta investigação, são observadas as cenas fílmicas retratando aspectos culturais brasileiros em que se percebe que as legendas - ou omissão delas - utilizam recursos imagéticos para a contextualização da narrativa.

Levando em conta a representação cultural, o termo 'cultura' é aqui definido como sendo "todo complexo que inclui conhecimentos, crenças, arte, moral, leis, costumes ou qualquer outra 
capacidade ou hábitos adquiridos pelo homem como membro de uma sociedade" (LARAIA, 2009, p. 25). Galeno et. al. (2008, p. 37) acrescentam que o termo cultura "é mais do que um conceito ou um princípio indicativo, mas a totalização dos processos que integram o modo como um problema é vivido". Nesse sentido, pode-se interpretar que a ideia de cultura está relacionada a uma prática cognitiva que auxilia o homem a criar formas de convívio em sociedade, favorecendo "a comunicação entre a experiência existencial e o saber constituído" (GALENO et. al., 2008.). A representação cultural, por sua vez, é "a mediação da cultura através da transcrição de signos transnacionais pela sociedade, que os adapta e os reconstrói, criando novas interpretações e significados, reterritorializando a cultura" (MATTELART, 2005, p. 97-8). Em outras palavras, ao assistirmos a um filme iraniano, por exemplo, fazemos uma leitura que incluirá nosso conhecimento prévio associado às novas informações daquele contexto fílmico, proporcionando um resultado que gerará uma releitura do contexto cultural representado no filme. Dessa maneira, os conceitos aqui apresentados parecem se adequar ao estudo realizado, pois incluem diversidade de tópicos que englobam a ideia de cultura, bem como a questão da representação de uma determinada cultura em novo contexto, sendo redefinida e reterritorializada, ou seja, a cultura, ao ser transportada para um novo contexto, também sofrerá influência desse novo local.

Ao tratar a ideia de multimodalidade, há a necessidade de também definir o termo Linguística de Corpus, que, segundo Sardinha (2000, p. 325) se ocupa da coleta e exploração de corpora, ou conjuntos de dados linguísticos textuais que foram coletados criteriosamente, com o propósito de servirem para a pesquisa de uma língua ou variedade linguística. Como tal, dedica-se à exploração da linguagem através de evidências empíricas, extraídas por meio de computador. Neste caso, vale reforçar que tal definição está situada na construção de um corpus formado por linguagem não verbal - imagens fílmicas. Seguindo esse raciocínio, os filmes sele- 
cionados são considerados como unidades de discurso (AUMONT; MARIE, 2004, p. 88), sendo o plano, i.e., a sequência de imagens, a unidade mais aparente, compreendida como a narrativa fílmica (AUMONT; MARIE, 2004, p. 47). A sequência de imagens é também chamada de segmentação, sendo uma sucessão de planos ligados por uma unidade narrativa (AUMONT; MARIE, 2004, p. 54) que traz sentido aos contextos apresentados.

Segundo McCarthy (2001, p. 125) e Meyer (2002, p. 5), algumas das vantagens de se construir um corpus multimodal são:

- Os corpora representam dados naturais não monitorados.

- A frequência do uso de palavras, frases e construções gramaticais não podem ser descobertas sem o uso de corpora.

- Para obter a informação sobre frequência, técnicas de linguística de corpus são a única opção, pois o ser humano tem apenas uma vaga noção a respeito da frequência de unidades lexicais e, portanto, precisa coletar dados de forma natural para obter resultados precisos sobre a frequência de uso de palavras.

- O processo introspectivo não é sistemático e é, definitivamente, menos sistemático do que o uso de corpora.

Seguindo tais características, acredita-se que a formação do corpus multimodal auxilia na demonstração de como a representação cultural - através da variação linguística nos diálogos e nas imagens fílmicas - é exposta, oferecendo maior possibilidade de compreensão dos contextos, a partir de situações reais sistematizadas pela criação do corpus.

\section{A formação do corpus multimodal}

Os critérios para determinar a estrutura de um corpus devem ser poucos, claramente separados um do outro e eficientes para 
delinear um corpus representativo da língua ou variedade em estudo (OLOHAN, 2004; VIANA; TAGNIN, 2010). Além disso, as amostras linguísticas para um corpus devem, sempre que possível, apresentar documentos inteiramente transcritos ou devem estar o mais próximo possível desse objetivo. Isso significa que as amostras diferirão em tamanho. O design e composição de um corpus devem ser documentados com informações sobre o conteúdo e justificativas das decisões tomadas. Ou seja, mesmo que o corpus de pesquisa seja aparentemente pequeno, sua representatividade será justificada a partir das propostas de pesquisa.

Portanto, o responsável pelo corpus deve ter noção de representatividade e equilíbrio. Essas noções devem ser usadas para guiar o design do corpus e a seleção de seus componentes, fazendo com que qualquer controle do tema em um corpus deva ser imposto pelo uso de critérios externos e não internos - as necessidades e propostas da pesquisa em si. É importante mencionar ainda que um corpus deve buscar homogeneidade de seus componentes e manter cobertura adequada, evitando textos sem fonte segura.

A seguir, serão comentadas algumas das imagens ${ }^{8}$, selecionadas para a formação de um corpus multimodal, contrastando-as com as legendas - ou omissão dessas.

\section{Analisando as imagens em contraste com legendas}

É importante mencionar que, não necessariamente, a exclusão de diálogos nas legendas é considerada positiva ou negativa. A intenção é de justificar, teoricamente, a razão da omissão de diálogos em contraste com as imagens de cenas específicas, buscando provar que a omissão de legendas, pelo menos em determinados casos, não causa falhas de comunicação entre a mensagem e o espectador. As análises são tratadas como problematizações em contraste com a teoria e metodologia aplicadas. 

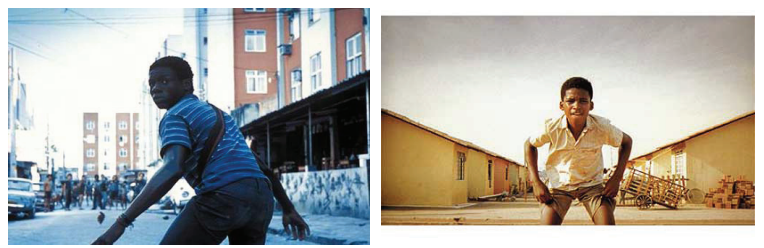

Figura 1: Cena inicial de Cidade de Deus, retomada no final do filme.

Esta é a cena, mencionada na Introdução, que marca a narrativa cronológica e a rima cinematográfica ${ }^{9}$ em flashback. Nela, o narrador-personagem, Buscapé, começa a contar a sua história no conjunto residencial Cidade de Deus e como se tornou o fotógrafo que retratou a história das gangues e do tráfico de drogas no local. A primeira imagem apresentada na Figura 1 mostra Buscapé de frente à gangue de Zé Pequeno, que ordena que Buscapé segure a galinha que fugiu do abate. Obedecendo, Buscapé tenta agarrar a galinha, mas é distraído pela gangue, que se alvoroça com a chegada da polícia, atrás de Buscapé. Nesse momento, Zé Pequeno pede para a gangue não fugir e começa a insultar os policias. A cena é traduzida nas legendas, que buscam descrever a linguagem de forma mais próxima possível da linguagem coloquial e agressiva do personagem Zé Pequeno, sendo ocultada quando o personagem continua sua ofensa à polícia, em plano de fundo, ou seja, como parte da imagem, ocorrendo em segundo plano da cena em evidência. O que parece importar, nesse momento, é o jogo de imagens, que volta no tempo para relatar a história da Cidade de Deus, quando os personagens eram crianças.

Por tal razão, parece haver lógica na omissão de legendas para reportar o que Zé Pequeno segue falando, uma vez que foi previamente relatado, nas legendas, que ele está afrontando os policiais e que não vai se intimidar por eles. O interesse maior parece ser a retomada cronológica marcada pelas imagens, bem como a descrição visual da época narrada. As legendas são assim apresentadas: 


\begin{tabular}{|l|l|}
\hline $\begin{array}{l}\text { Zé Pequeno - Aí, 'muleque', se- } \\
\text { gura a galinha aí pra mim. Pega a } \\
\text { galinha aí. }\end{array}$ & $\begin{array}{l}\text { - Hey, kid! Get that chicken! Get } \\
\text { that chen! }\end{array}$ \\
\hline Gangue - Polícia! & - Shit the cops! \\
\hline $\begin{array}{l}\text { Zé Pequeno - Não corre, não! Não } \\
\text { corre, não! Porra! }\end{array}$ & - Don't fucking run off! \\
\hline Zé Pequeno - Me dá isso aqui! & - Give me that. \\
\hline $\begin{array}{l}\text { Zé Pequeno - Aí, cabeção! Seus } \\
\text { viado! }\end{array}$ & $\begin{array}{l}\text { - Hey, Melonhead! You fucking } \\
\text { fag! }\end{array}$ \\
\hline $\begin{array}{l}\text { Buscapé - Minha fotografia podia } \\
\text { mudar minha vida. }\end{array}$ & $\begin{array}{l}\text { - A picture could change my life, } \\
\text { but... }\end{array}$ \\
\hline $\begin{array}{l}\text { Buscapé - Mas, na Cidade de } \\
\text { Deus, se correr o bicho pega... }\end{array}$ & $\begin{array}{l}\text {...in the City of God, if you run } \\
\text { away, they get you... }\end{array}$ \\
\hline Buscapé - se ficar o bicho come. & $\begin{array}{l}\text { - ... and if you stay, they get you } \\
\text { too. }\end{array}$ \\
\hline $\begin{array}{l}\text { Zé pequeno fala a fundo da nar- } \\
\text { ração, mas sem registro. }\end{array}$ & - They're coming for us. \\
\hline $\begin{array}{l}\text { Buscapé - E sempre foi assim, des- } \\
\text { de que eu era criança. }\end{array}$ & $\begin{array}{l}\text { It's been that way ever since I was } \\
\text { a kid... }\end{array}$ \\
\hline
\end{tabular}

Tabela 1: Legendas referentes à primeira cena de Cidade de Deus.

As legendas apresentadas acima mostram a fala de Zé Pequeno e representa o início-final do filme, com a narração da história da Cidade de Deus por Buscapé. A narração vai girar em torno dessa cena e dessa fala, representada mais especificamente pela narração de Buscapé. A fala do personagem Zé Pequeno é marcada no início para mostrar o tom agressivo e desafiador, mas logo a fala do narrador ganha relevância e a fala de Zé Pequeno é ocultada na legenda. Aqui, o termo 'relevância' segue a ideia descrita por Gutt (2000), sobre a Teoria da Relevância envolvendo Tradução, que reforça a importância de retratar apenas o que parece essencial a um determinado público, contexto e situação, principalmente no 
trabalho com legendas. As imagens em sequência vão marcar a força do que é dito em plano de fundo, dispensando a necessidade de apresentar a fala em formato de legenda. Portanto, não parece haver falha de comunicação com a omissão da fala de Zé Pequeno para o telespectador, que compreende o que se passa em tela, através das imagens e da fala inicial apresentada. A seguir, mais uma cena de Cidade de Deus é apresentada.

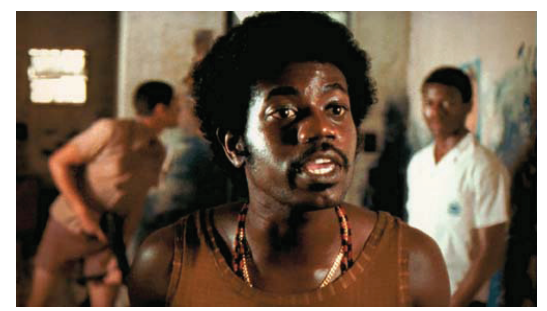

Figura 2: Cena de Cidade de Deus, com Zé Pequeno, na Boca dos Apês, e Buscapé ao fundo.

A Figura 2 mostra a cena em que Zé Pequeno toma a Boca dos Apês e se apresenta não mais como Dadinho, seu apelido de infância, mas como Zé Pequeno. Na cena em destaque, Buscapé observa a chance de vingar a morte de seu irmão, que foi assassinado por Dadinho. Na narrativa, Buscapé demonstra seu medo e índole pacífica, apesar de residir em um local violento e em constante convívio com essa realidade agressiva. A linguagem da cena é violenta, com traços de coloquialidade e do contexto local, que são difíceis de transportar para novo contexto linguístico. Além disso, dessa vez, quem aparece em plano de fundo é o narrador-personagem, Buscapé. Seguem as legendas correspondentes à cena apresentada:

\begin{tabular}{|l|l|}
\hline Zé Pequeno - Que tal, Neguinho. & - Hey, Blacky. \\
\hline $\begin{array}{l}\text { Neguinho - Porra, Dadinho. Como } \\
\text { é que tu chega assim na minha } \\
\text { boca? }\end{array}$ & -You show up like this at my place? \\
\hline
\end{tabular}




\begin{tabular}{|c|c|}
\hline $\begin{array}{l}\text { Zé Pequeno - Quem falou que a } \\
\text { boca é tua, rapá? }\end{array}$ & - Who said it was your place? \\
\hline Neguinho - Qual é, Dadinho? & - Something wrong, Li'l Dice? \\
\hline Zé Pequeno - Dadinho o caralho. & - Li'l Dice my ass. \\
\hline $\begin{array}{l}\text { Zé Pequeno - Meu nome agora é } \\
\text { Zé Pequeno, porra. }\end{array}$ & - My name's Li'l Z' now. \\
\hline $\begin{array}{l}\text { Comparsa de Zé Pequeno - O nome } \\
\text { dele é Zé pequeno, tá entendendo? }\end{array}$ & - His name's Li'l Z', see? \\
\hline $\begin{array}{l}\text { Zé Pequeno - E tu vai cair, fil'a } \\
\text { da puta. }\end{array}$ & - You're a goner, bastard. \\
\hline $\begin{array}{l}\text { Bené - Mata, não. Mata, não, que } \\
\text { ele já entendeu. }\end{array}$ & - Don't kill him. He understands. \\
\hline Bené - Neh não, Neguinho? & - Right, Blacky? \\
\hline $\begin{array}{l}\text { Neguinho - Pode ficar com a boca } \\
\text { aí, que eu não quero nada, não. }\end{array}$ & $\begin{array}{l}\text { - It's all yours, I don't want any- } \\
\text { thing. }\end{array}$ \\
\hline $\begin{array}{l}\text { Neguinho - Vou sair saindo, que } \\
\text { eu não quero arengação, valeu? }\end{array}$ & - I don't want no trouble, okay? \\
\hline $\begin{array}{l}\text { Buscapé - O certo era eu aproveitar } \\
\text { aquela chance pra vingar a morte } \\
\text { do meu irmão. }\end{array}$ & $\begin{array}{l}\text { - I should have taken this chance to } \\
\text { avenge my brother's death. }\end{array}$ \\
\hline \multicolumn{2}{|l|}{$\begin{array}{l}\text { Neguinho falando ao fundo - } \\
\text { sem registro. }\end{array}$} \\
\hline $\begin{array}{l}\text { Zé Pequeno - Tu vai ficar vivo, } \\
\text { Neguinho. Mas, vai ficá vivo aqui, } \\
\text { trabalhando pra nós, tá escutando? }\end{array}$ & $\begin{array}{l}\text { - You'll live, but you'll work for us, } \\
\text { understand? }\end{array}$ \\
\hline Buscapé - Pensar é fácil. & - That's easy to say... \\
\hline
\end{tabular}

Tabela 2: Cena da tomada da Boca dos Apês em Cidade de Deus.

Apesar de o narrador-personagem aparecer em plano de fundo, sua fala é a mais importante em todo o filme e ela não é omitida nas legendas, que seguem retratando os diálogos entre as gangues. En- 
tretanto, mais uma vez, um trecho de fala - dessa vez do Neguinho - não é legendado, pois passa também para segundo plano, sendo mais relevante focar na fala de Buscapé - mesmo sem aparecer em plano central na cena -, e de Zé Pequeno. A omissão da fala não parece ser um problema para a compreensão e desenrolar da cena, já que as imagens e diálogos apresentados parecem retratar com precisão o que acontece na sequência fílmica, como na primeira cena do filme mostrada anteriormente.

A cena a seguir é do filme $O$ Auto da Compadecida e apresenta falas e contextos que descrevem um Brasil com características locais ainda mais específicas - o Sertão da Paraíba, em uma época histórico-cultural mais remota - a década de 1930.

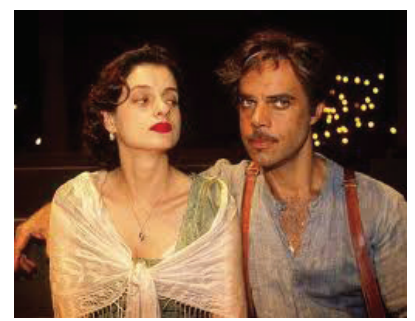

Figura 3: Cena de $O$ Auto da Compadecida, com Chicó, Dora e o marido padeiro.

A cena relata uma conversa entre Dora, a mulher do padeiro, e Chicó, logo após a morte da cachorra de Dora, que tem funeral e enterro conduzidos pelo padre da cidade. A conversa segue com traços de coloquialidade e prosódia dos personagens, marcando o contexto e situação em que vivem - Chicó, contando seus 'causos' e Dora, em seu jogo de sedução. O diálogo é relatado nas legendas, mas a linguagem e melodia são transformadas, por não ser possível transferir tais características linguísticas e prosódicas ao novo contexto cultural que, obviamente, não é capaz de manter similaridade absoluta entre termos e características. A sequência de imagens 
segue buscando auxiliar o público a compreender o que se passa nas cenas. Seguem as legendas da cena em destaque:

\begin{tabular}{|l|l|}
\hline $\begin{array}{l}\text { Chicó - Como vai a senhora? Já tá } \\
\text { mais consolada? }\end{array}$ & - How are you? Do you feel better? \\
\hline Dora - Consolada? & - Feel better? \\
\hline $\begin{array}{l}\text { Dora - Como? Se além de perder } \\
\text { minha cachorra tive que gastar } 9 \\
\text { contos p'ela se enterrá? }\end{array}$ & spent 150 crowns on the funeral. \\
\hline $\begin{array}{l}\text { Chicó - E foi barato. A senhora } \\
\text { pagou 9 contos pro padre benzê } \\
\text { um bicho. }\end{array}$ & a critter. \\
\hline $\begin{array}{l}\text { Chicó - Eu já vi pagarem } 15 \text { contos } \\
\text { pr'um bicho benzê uma pessoa. }\end{array}$ & - I once saw a critter bless a man bless \\
for 200. \\
\hline $\begin{array}{l}\text { Dora - Espie, que bicho foi esse, } \\
\text { Chicó? }\end{array}$ & - What critter was that? \\
\hline $\begin{array}{l}\text { Chicó - Foi um papagaio que eu } \\
\text { tive. }\end{array}$ & - A parrot I had. \\
\hline $\begin{array}{l}\text { Chicó - Quando ele nasceu eu tra- } \\
\text { balhava no seminário. Ele tanto } \\
\text { ouvia as aulas que sabia a bíblia } \\
\text { de cor. }\end{array}$ & learned the Bible by heart. \\
\hline $\begin{array}{l}\text { Chicó - Depois eu fui morar num } \\
\text { lugar que só tinha padre a mais de } \\
10 \text { léguas de distância. }\end{array}$ & - Then, I moved to a town without \\
\hline $\begin{array}{l}\text { Chicó - O bicho que costumava } \\
\text { dispensar o sacramento. }\end{array}$ & - The parrot dispensed the sacra- \\
\hline $\begin{array}{l}\text { Dora - E que fim levou esse pap- } \\
\text { agaio? }\end{array}$ & - What happened to the parrot? \\
\hline $\begin{array}{l}\text { Chicó - Se converteu ao Protes- } \\
\text { tantismo e foi viver numa igreja } \\
\text { Batista lá em Glória de Goitá. }\end{array}$ & $\begin{array}{l}\text { - He became a Protestant and left } \\
\text { Goitá. }\end{array}$ \\
\hline $\begin{array}{l}\text { Chicó - Há uns dois anos, soube } \\
\text { que morreu de velhice. }\end{array}$ & - I heard he died of old age. \\
\hline
\end{tabular}




\begin{tabular}{|l|l|}
\hline $\begin{array}{l}\text { Dora - E como morreu de velhice } \\
\text { se você disse que viu ele nascer? }\end{array}$ & $\begin{array}{l}\text { - How could that be... } \\
\text {...if you say you saw its birth? }\end{array}$ \\
\hline $\begin{array}{l}\text { Dora - Papagaio vive mais de } 100 \\
\text { anos. }\end{array}$ & - Parrots live to be over 100. \\
\hline $\begin{array}{l}\text { Chicó - Não sei, só sei que foi as- } \\
\text { sim. }\end{array}$ & - I don't know, but so it was. \\
\hline $\begin{array}{l}\text { Dora - Ai, Chicó, eu me sinto tão } \\
\text { sozinha depois que a minha ca- } \\
\text { chorrinha morreu. }\end{array}$ & - Chicó, I've been so terribly lonely little bitch died! \\
\hline $\begin{array}{l}\text { Chicó - Carece da senhora arrumá } \\
\text { outro bichinho de estimação. }\end{array}$ & - You should get another pet. \\
\hline Dora - E o que você sugere? & - And what would you suggest? \\
\hline $\begin{array}{l}\text { Chicó - Um canário é bom pra } \\
\text { alegrá. }\end{array}$ & - A canary, to cheer you up. \\
\hline
\end{tabular}

Tabela 2: Cena de Chicó, Dora e padeiro em O Auto da Compadecida.

Em O Auto da Compadecida, as legendas não são omissas com frequência, mas adequadas à língua-alvo. O que é omitido são os traços de coloquialismo e de prosódia dos diálogos, pois não há, de fato, similaridade linguística entre o português brasileiro (paraibano) e a língua inglesa. Assim, as imagens parecem servir como tradução fundamental para o espectador, que observa o que é relatado nas sequências de imagens e compreende o desenrolar da trama. Até que ponto as imagens são suficientes para transmitir o humor e jogo irônico dos personagens - mais uma vez de acordo com Aristóteles (1999) - deverá ser analisado em estudo mais aprofundado com relação ao corpus multimodal, aqui, em fase de construção. 


\section{Conclusão}

Este artigo apresenta uma investigação em fase seminal, com dados ainda sendo coletados e teoria em desenvolvimento. Pesquisadores de áreas como Ciências Sociais, Antropologia, Filosofia, Estudos Culturais, Linguística e Estudos da Tradução têm demonstrado interesse em analisar como a linguagem é usada para construir representações culturais de forma escrita e oral. O Cinema, por sua vez, em relação à área específica de Letras, parece dialogar, por enquanto, de forma mais próxima à Literatura do que com os Estudos da Tradução. Este trabalho surge para mostrar a necessidade de maior investigação intersemiótica sobre questões fílmicas em contexto tradutório, que ultrapassam os limites da linguagem verbal.

Outro destaque é apresentado aqui envolvendo a necessidade de se incorporar, mais especificamente, a tradução cultural aos Estudos da Tradução, evidenciando questões sobre representação cultural. Nesse sentido, corrobora-se a visão de Cronin (2009, p. 26 - tradução minha) de que "[o] cinema se tornou tradução a partir de outros meios. Com o intuito de favorecer a tradução de uma comunidade multilingual e multiétnica para consumidores prontos a reagir a um produto em uma língua, traços de particularismo tiveram que ser apagados" ${ }^{10}$. A citação reforça a questão relacionada à representação cultural aqui discutida, ao mostrar que o favorecimento a uma comunidade multilingual e multiétnica gera a adaptação de uma determinada cultura a um novo local. Dessa forma, a cultura retratada em contexto fílmico sofre influência - e influencia - o local de recepção -, reforçando a ideia de que "não há cultura sem mediação, não há identidade sem tradução. Cada sociedade retranscreve os signos transnacionais, adapta-os, os reconstroi, reinterpreta-os, reterritorializando-os, "ressemantiza-os'" (MATTELART, 2005, p. 97-8). Além disso, merece também destaque a visão de Cronin (2009, p. 38) sobre a importância dada ao sotaque e à variação 
linguística dentro de uma mesma língua, marcando diferenças de classe, questões de poder, identidade regional e nacional, bem como o trabalho de integração dessas comunidades em cenários e épocas diversas.

Corroborando, também, a visão de Cronin (2009), Galeno et. al. (2008, p. 14) afirma que há boa comunicação do cinema brasileiro com o telespectador, pois uma característica do público brasileiro é gostar de se reconhecer em tela, "ver a estória e os sotaques do Brasil, no que a ausência da legenda ajuda". Nesse caso, fala-se do público brasileiro. Entretanto, problematizando a questão linguística, mesmo em território nacional, às vezes torna-se difícil a compreensão de diálogos regionalizados, e questiono até que ponto o uso de legendas pode ser um excesso. Os autores seguem afirmando que o cinema brasileiro aproxima produtores e espectadores, personagens e pessoas reais, envolvendo todos no processo de comunicação. Essas características são percebidas nas cenas destacadas, que demonstram essa boa recepção do público brasileiro às obras selecionadas.

Dessa forma, conclui-se este artigo com a afirmação de Galeno et. al. (2008, p. 24) de que "o cinema brasileiro fala às minorias, embora o circuito comercial de exibição não privilegie produções fora do mainstream". Segundo Mattelart (2005, p. 37), "o cinema se torna o emblema das relações de força que vão marcar a internacionalização da produção cultural". Para se adequar ao cinema, deve-se adotar o modelo hollywoodiano, uma vez que, segundo o autor, a indústria do cinema norteamericano ganha fisionomia oligopólica a partir de 1920. Em contexto nacional, aparentemente, o público rejeita esse modelo para a produção nacional, aceitando-a e se identificando com ela. Questionamentos a serem posteriormente investigados dizem respeito à recepção desses filmes em contexto internacional e se as imagens, por si só, são capazes de representar culturalmente os Brasis relatados nos filmes selecionados. 


\section{Notas}

1. Agradeço ao Grupo de Pesquisa registrado na CAPES 'Estudos da Tradução: Teoria, Prática e Formação do Tradutor' (UFCG) pelo apoio e trocas acadêmicas.

2. Gênero: Drama. Duração: 135 min. Ano: 2002. Direção: Fernando Meirelles.

3. Gênero: Comédia. Duração: 104 min. Ano: 2000. Direção: Guel Arraes.

4. Termo de origem grega (kômikós), derivado do latim comicu. De ampla aplicação, traduz, textualmente, a conciliação de ideias ou de situações aparentemente irreconciliáveis. Essa conciliação é produzida através de um raciocínio engenhoso com a intenção de produzir o riso através do texto literário. Disponível em $<$ http://www.edtl.com.pt/index.php?option $=$ com_mtree\&task $=$ viewlink\&link_ $\mathrm{id}=667 \&$ Itemid $=2>$ Acesso em 09 de julho de 2012 .

5. LINS, Paulo. Cidade de Deus. Editora Companhia de Bolso, 1997, 403 páginas. ISBN 8535911922.

6. Gênero: Suspense e Crime. Duração: 154 min. Ano: 1994. Direção: Quentin Tarantino.

7. "Tradução de Multimídia” é a quarta das doze áreas de pesquisa em Estudos da Tradução elencadas por Wiliam e Chesterman (2002, p. 13).

8. Disponível em <http://www.google.com.br/search?q=imagens + cida $\mathrm{de}+\mathrm{de}+$ deus\&hl $=$ pt-BR\&prmd $=$ imvns $\&$ tbm $=$ isch\&tbo $=u \&$ source $=$ uni

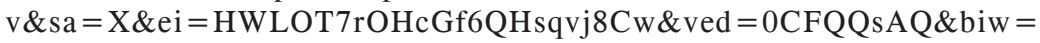
$1366 \& b i h=667>\quad$ e $\quad$ http://www.google.com.br/search?q=imagens + cida $\mathrm{de}+\mathrm{de}+$ deus \&hl $=$ pt-BR\&prmd $=$ imvns \&tbm $=$ isch\&tbo $=$ u\&source $=$ uni

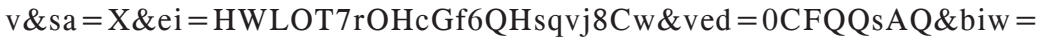
$1366 \& \mathrm{bih}=667 \# \mathrm{hl}=\mathrm{pt}-\mathrm{BR} \& \mathrm{tbm}=\mathrm{isch} \& \mathrm{sa}=1 \& \mathrm{q}=$ imagens $+\mathrm{o}+$ auto $+\mathrm{da}$ + compadecida\&oq $=$ imagens $+\mathrm{o}+$ auto $+\mathrm{da}+$ compadecida $\& \mathrm{aq}=\mathrm{f} \& \mathrm{aq} \mathrm{i}=$ $\& \mathrm{aql}=\& \mathrm{gs} 1=\mathrm{img} .3 \ldots 65347.71628 .0 .71877 .35 .18 .0 .16 .0 .9 .368 .4033 .2-$ -8j6.14.0..0.0.GWMVRXS6_Tg\&pbx $=1 \&$ bav $=$ on.2,or.r_gc.r_pw.r_qf.,cf.os $\mathrm{b} \& \mathrm{fp}=6967338 \mathrm{bde} 05 \mathrm{c} 1 \mathrm{c} 7 \& \mathrm{biw}=1366 \& \mathrm{bih}=667>$ acesso em 05/06/2012. 
9. O termo rima cinematográfica remete a cenas curtas que costumam evocar sentimentos ou lembranças dos personagens. Disponível em $<$ http://dicasderoteiro. com/2010/01/06/rima-cinematografica/ > . Acesso em: 06 jun. 2012.

10. Cinema became translation by another means. In order to favour the translation of a multilingual and multiethnic community into a mass body of consumers ready to respond to a product in one language, traces of particularism had to be erased. (CRONIN, 2009, p. 26).

\section{Referências}

ARISTÓTELES. Poética. Tradução de Baby Abraão. São Paulo: Nova Cultural, 1999. (Os Pensadores).

AUMONT, Jaques; MARIE, Michel. A Análise do Filme. Trad. Marcelo Félix. Lisboa: Edições Texto \& Grafia Ltda, 2004.

BROWNE, Nick. The rhetoric of film narration. Ann Arbor: UMI Research Press, 1982.

CIDADE de Deus. Direção de Fernando Meirelles. Produção de Tulé Peake. Brasil: O2 Filmes, 2002. DVD (130 min).

CRONIN, Michael. Translation goes to the movies. New York: Routledge, 2009.

GALENO, A. et. al. Brasil em Tela: cinema e poéticas do social. Porto Alegre: Sulina, 2008.

GUTT, Ernst-August. Translation as Interlingual Interpretive Use. In: VENUTI, Lawrence (Ed.). The Translation Studies Reader. London: Routledge, 2000. p. 376-396. 
JAKOBSON, Roman. On Linguistic Aspects of Translation. In: VENUTI, Lawrence (Ed.). The Translation Studies Reader. London: Routledge, 2000. p. 113118.

LARAIA, R. B. Cultura: um conceito antropológico. Rio de Janeiro: Ed. Jorge Zahar, 2009.

LUND, K. The importance of gaze and gesture in interactive multimodal explanation. Language Resources and Evaluation, 41(3), p. 289-303, 2007.

MATTELART, Armand. Diversidade Cultural e Mundialização. Trad. Marcos Marcionilo. São Paulo: Parábola, 2005.

McCARTHY, M. J. Issues in Applied Linguistics. Cambridge: Cambridge University Press, 2001.

MEYER, C. F. English corpus linguistics: An introduction. Cambridge: Cambridge University Press, 2002.

O AUTO da Compadecida. Direção de Guel Arraes. Produção de Lia Renha. Brasil: Globo Filmes, 2000. DVD (104 min).

OLOHAN, Maeve. Introducing Corpora in Translation Studies. New York: Routledge, 2004.

ORICCCHIO, Luiz Zanin. Cinemanovo. Um balanço crítico da retomada. São Paulo: Estação Liberdade, 2003.

SARDINHA, Tony Berber. Linguística de Corpus: histórico e problemática. Delta, vol. 16, n. 2, p. 323-367, 2000.

VANOYE, Francis. Récit, écrit, récit filmique. Paris: CEDIC, 1979. (Textes et non texts)

VENUTI, Lawrence. The Translation Studies Reader. New York: Routledge, 2000. 
VIANA, Vander; TAGNIN, Stella E. O. (Org.). Corpora no ensino de línguas estrangeiras. São Paulo: Hub Editorial, 2010.

WILliAMS, J.; CHESTERMAN, A. The Map. A Beginner's Guide in Translation Studies. Manchester (UK): St Jerome, 2002.

Recebido em: 15/01/2014

Aceito em: 23/04/2014 
